\title{
Mechanism for the Upward Fire Spread through Balconies based on an Investigation and Experiments for a Multi-story Fire in High-rise Apartment Building
}

\author{
Akihiko Hokugo \\ Graduate School of Science and Technology, Kobe University \\ 1-1 Rokko-dai, Nada, Kobe, 657-8501, Japan
}

\author{
Yuji Hasemi \\ Department of Architecture, Waseda University \\ 3-4-1, Ohkubo, Shinjuku, Tokyo, 169-8555, Japan
}

Yoshihiko Hayashi and Masashi Yoshida

Building Research Institute, Ministry of Construction

1 Tachihara, Tsukuba, 305-0802, Japan

\begin{abstract}
Summary of experiments for the investigation of a fire which caused an upward fire spread for over 12 floors through balconies in a high-rise apartment complex is reported. The experiments include indoor tests to obtain fire properties of vertical PMMA fences and outdoor tests with a full scale model of the balcony. The test results suggest significance of the increase of total flame height through merging of flames and cooperative effect of the burning of PMMA fences and combustibles on the balconies for the generation of a tall flame enough to cause ignition on the upper floor.
\end{abstract}

KEYWORDS: upward fire spread, PMMA, balconies

\section{INTRODUCTION}

A fire which started in an apartment unit on the $9^{\text {th }}$ floor of a 20 story apartment complex in Hiroshima-City in the afternoon, $28^{\text {th }}$ October 1996 , developed to the $20^{\text {th }}$ floor through the balconies in 30 minutes and resulted in the total burning of 16 apartment units and partial fire damage to 11 apartment units. Figure 1 is a picture taken during the fire and Figure 2 is a summary of the fire damage. The weather was cloudy and there was approximately $1 \mathrm{~m} / \mathrm{s}$ weak wind from northeast during the fire. Almost thorough process of the floor-to-floor growth of the fire was recorded with a video camera accidentally by a resident, and is summarized in Figure 3. Although the fire growth from the $9^{\text {th }}$ floor to the $12^{\text {th }}$ floor was rather slow, the vertical fire spread on the $13^{\text {th }}$ floor and higher was surprisingly fast; it took only $20-30$ seconds for the fire to proceed upward by one floor. 
During this fast fire growth, no significant fire was observed in the rooms on the $12^{\text {th }}$ floor and higher, which implies that the combustibles on the balconies were the principal source of the fuel to maintain the fast vertical fire spread. It was the first significant multistory fire in high rise buildings in Japan, and the extremely fast vertical fire spread drew strong interest by fire experts. The Ministry of Construction organized an investigation committee on this fire, and Building Research Institute conducted large-scale experiments as a part of this activity [1 -3$]$. This report conveys summary of the main results of the investigation and the experiments

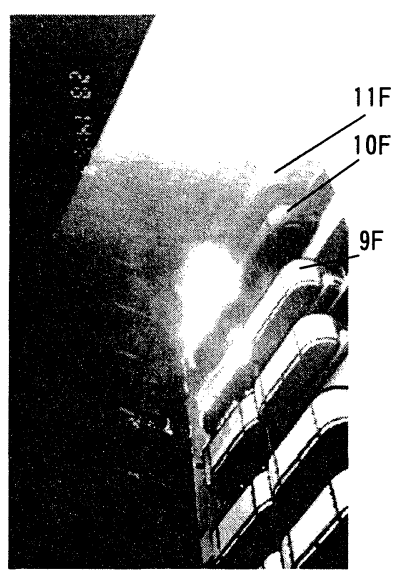

(a) 20min after estimated fire outbreak

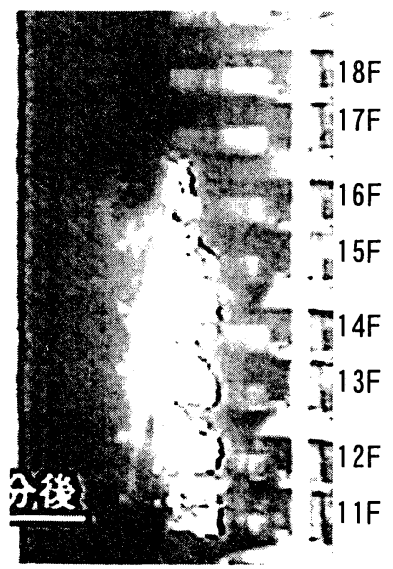

(c) $24 \mathrm{~min}$ after estimated fire outbreak

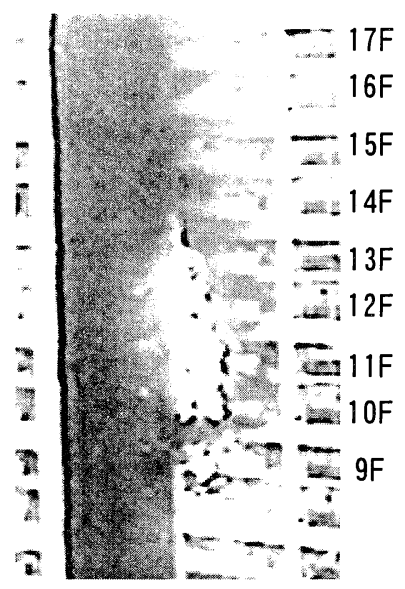

(b) $22 \mathrm{~min}$ after estimated fire outbreak

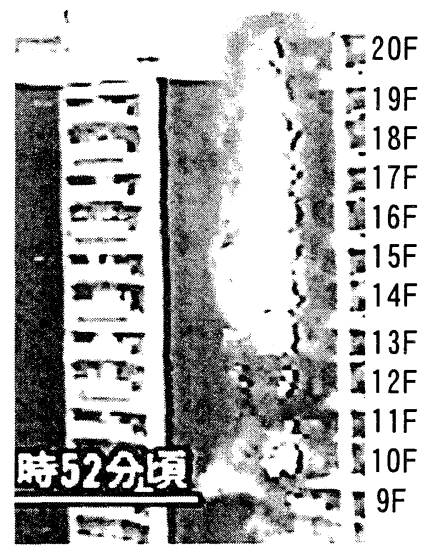

(d) 26min after estimated fire outbreak

Figure 1 Picture Records of the Fire (b-d from NHK broadcast) 

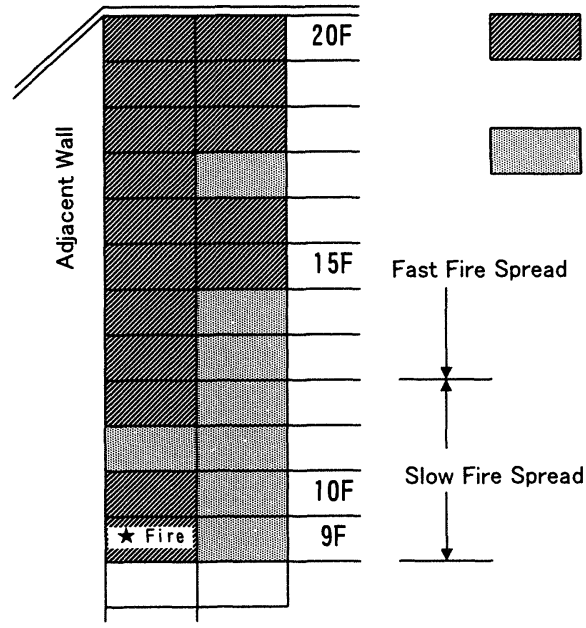

Apartment Unit Fully

Damaged by Fire

Apartment Unit Partly

Damaged by Fire

Figure 2 Fire Damage Summary (Interior)

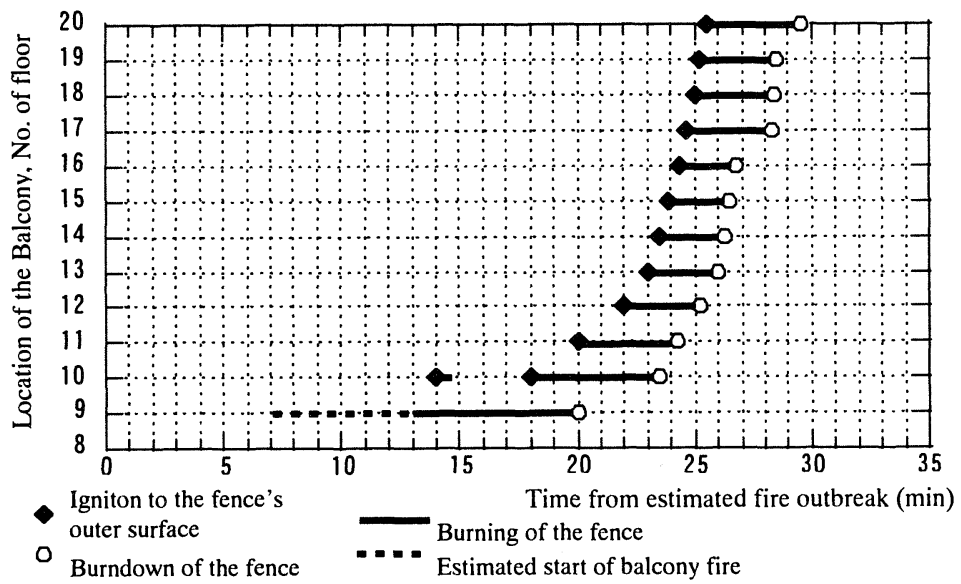

\section{Figure 3 Summary of the Vertical Fire Growth through Balconies}

\section{THE BUILDING}

The apartment building was built in 1972 for generally low-income families with steelreinforced concrete frame structure and is owned and operated by Hiroshima-City. The complex consists of 2,964 dwellings in total and has a rather complicated plan as seen in Figure 4 . The 
shopping mall between the building and the road inside the developed area prevented fire engines from approaching to the burning façade directly. The building has open-air corridors on every other floor, and the apartments on a floor without such corridor are accessible through a stairway down to the corridor; the general plan and the section of the apartments are shown in Figure 5.

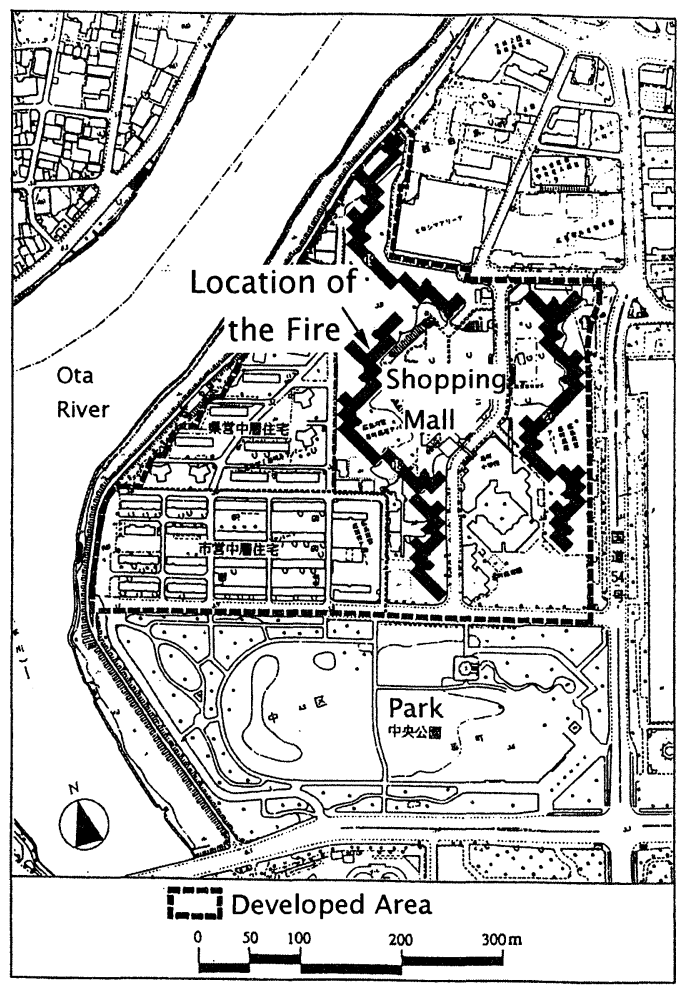

Solid part represents high-rise buildings.

Figure 4 Layout of the Hiroshima Motomachi Apartment Complex

Floor area of each apartment unit is $36 \mathrm{~m}^{2}-42 \mathrm{~m}^{2}$. The vertical and horizontal fire separations are reinforced concrete slabs and walls of either concrete blocks or reinforced concrete respectively. The balcony-side external wall of each apartment unit consists of concrete load bearing frames and normal and wired glass windows; there is no solid wall with concrete or metal. The $1.6 \mathrm{~m}$ deep balcony had a 1 meter tall $8-20 \mathrm{~mm}$ thick polymethylmethacrylate (PMMA) fence. The fence was supported by a steel frame around the skirt of the balcony, and there was $35 \mathrm{~mm}$ gap between the fence and the skirt of the balcony floor. Partly for the 
tightness of the size of the apartment units and partly because the most of the residents are aged and have continued to live in the same unit over 20 years, fire load density in the apartment units was generally high; these circumstances generally resulted in notable amount of live loads, generally combustibles, left on the balconies. The features of the design and construction of this building are believed to weaken the performance for the prevention of fire spread through the façade. Three fires had already caused fire penetrations to apartment units on upper floors before the 1996 fire through different routes of the external wall at this complex.

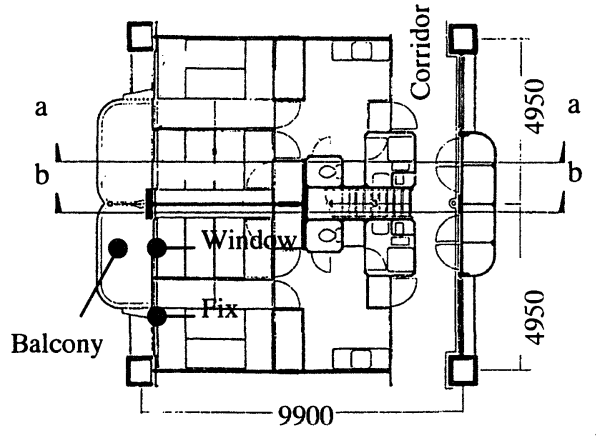

Dwelling Plan

for even-numbered floors

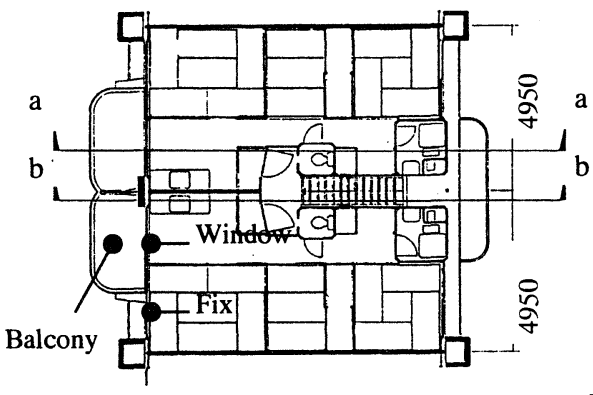

Dwelling Plan for odd-numbered floors

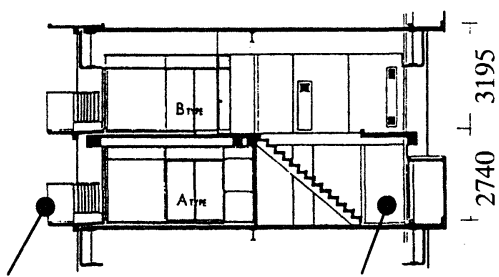

Corridor

b-b section

(stair and public space)

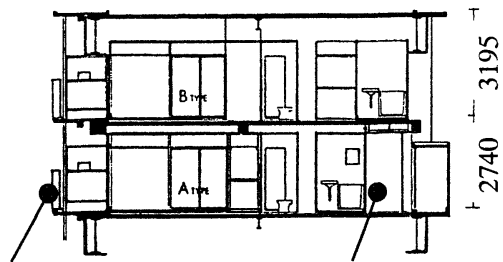

Corridor

Fence

$$
\begin{aligned}
& \text { a-a section } \\
& \quad \text { (apartments) }
\end{aligned}
$$

\section{Figure 5 Apartment Units in the Hiroshima Motomachi Apartment Complex}

\section{PRE-EXPERIMENT STUDY FOR THE MECHANISM OF THE FAST FIRE SPREAD}

According to the video record of the fire, the PMMA fences were ignited directly by the external flame developing from the lower floors during the fast flame spread. It means that the time for fire spread from floor to floor, 20 -30 seconds, should be equivalent with the time to ignition of 
the fence material exposed to the external flame. According to the ignitability tests data, the time to ignition of PMMA becomes 30 seconds or shorter only if the level of the external heat flux becomes $50 \mathrm{~kW} / \mathrm{m}^{2}$ or higher. Previous wall flame heat transfer correlations on relatively large fires suggest correspondence of this rather high heat flux with the exposure to an intermittent flame from a $10^{-1}-10^{0} \mathrm{MW}$ fire [4]; frequent attack on the fences by intermittent flames were observed in the video tape during the fast fire spread. Repeated generation of such flames which were tall enough to cover the fence of the upper floor is believed as the main factor to maintain the fast flame spread. This suggests importance of the mechanism generating such a tall flame along the balconies.

PMMA is a very common laboratory material for surface burning. According to the knowledge on its combustibility, it was anticipated that the burning of a single vertical surface of a $1 \mathrm{~m}$ tall PMMA can generate around $2 \mathrm{~m}$ tall flame, which is not enough to reach the upper floor. On a few balconies there were certainly considerable amount of combustibles which may be enough to generate an enough tall flame. The video record actually shows a very tall flame developing from inside the fence of the $16^{\text {th }}$ floor. However, large combustibles on only a few floors should not offer an enough explanation for the thorough process of the fast fire spread for over 8 floors.

Several possible causes and mechanisms stood for the surprisingly fast vertical fire spread though the balconies. These include:

1) relative location of the fire to the whole building

2) simultaneous two-face burning of the polymethylmethacrylate (PMMA) fence

3) simultaneous burning of the fence and combustible objects on balconies

Regarding the first possibility, it is widely known that a diffusion flame in fire becomes approximately $30-50 \%$ taller in a corner than in an unconfined space due to restriction of air entrainment [5]. Also, radiative interaction between the walls around the corner is believed to increase surface heat flux and accelerate fire spread in a corner configuration. Although this well known principle was naturally recalled as it was in the corner of the building that the vertical fire spread took place, the fire growing along the balcony seldom flowed into the corner during the fast fire spread. It was finally concluded that this mechanism never played an important role in the fast fire spread although it may have had significant influence during the fire spread over the first 2 or 3 floors, which was however rather slow.

If the two surfaces of a vertical combustible slab burns simultaneously, heat release rate is believed to become twice, which should increase the flame height by around $60 \%$ [6]. If a single surface burning of PMMA produces a $2 \mathrm{~m}$ tall flame, its two-face simultaneous burning may produce $3.2 \mathrm{~m}$ tall flame, enough tall to reach the upper floor. Even if the heat release from the combustibles on any balcony is not enough to reach the upper floor, any combustible object with heat release rate comparable with the single surface burning of PMMA may produce an enough tall flame if it burns with the fence. Within this context, it is still important to clarify what mechanism leads to the both-face burning of PMMA or to the simultaneous burning of the fence and the combustibles. The gap between the fence and the balcony slab was considered as a possible route for the penetration of a flame developing outside the fence into the inner part of the balcony. 
However, from various evidence, it was thought that neither of the both surface PMMA burning nor the simultaneous burning of the fence and some combustibles might yet be enough to support a tall flame enough to cover the whole surface of the $1 \mathrm{~m}$ fence of the upper floor. The concept of an "accumulation of excess flames from multiple burning balconies" was introduced to explain the thorough process of the fast upward fire spread. With the entrainment and mixing as the principal elementary process controlling the flame height, it can be anticipated that, once the height of the flame from each burning balcony exceeds the floor-to-floor interval distance, flames from different floors merge into a very tall flame whose flame height is controlled by the total heat release rate.

Preheating of the PMMA fence and the combustibles by the fire plume from the lower floors was anticipated as another mechanism which may have supported the acceleration of the fast flame spread.

\section{THE EXPERIMENTS}

Experiments have been conducted using mock-ups of the balconies to verify the estimated causes and mechanisms for the fast vertical fire spread through the balconies. Investigation has been made on the influence of both-face burning of a PMMA fence on the flame height and the flame heating, and increase of flame height by merging of flames from discrete vertical fuels. A detailed mechanism of the vertical fire spread especially for an element from the ignition of either the PMMA fence or any of the combustible packages on a balcony floor to the full involvement of the balcony and the fence into fire has been examined. Firstly, a series of indoor tests were carried out to measure heat release rate and flame lengths for different scenarios of the burning of the PMMA fence. Secondly, a series of outdoor tests using a fullscale mock-up were conducted in order to see the merging effects and the detailed process of the fire spread within and in the neighborhood of a balcony. The full-scale mock-up has been built to reproduce a façade of two stories with PMMA fences and balconies loaded with combustible packages for a typical apartment. A roof with a PMMA fence has also been added to the top of the mock-up.

\section{Increase of Flame Height by the Both-face Burning of Vertical PMMA}

A series of indoor tests were carried out to quantify the ignition and burning behavior of a single vertical PMMA fence with a $1 \mathrm{~m}$ tall, $1 \mathrm{~m}$ wide and $10 \mathrm{~mm}$ thick PMMA slab beneath a smoke collection hood (Figure 6). The specimen was supported with a steel frame and was confined with cement board at the lateral edges to maintain a two-dimensional fire. A line propane burner was used as a pilot flame. Heat release rate was measured by the oxygen consumption method. Because of the limitation of the height of the hood the tests cannot reproduce the fire spread from a floor to upper floor. Five tests with different preheating and pilot flame conditions were conducted. The conditions were as follows; (A-1) ignition with a $23 \mathrm{~kW} / \mathrm{m}$ line flame at one side of the slab beside tail edge, (A-2) ignition with a $46 \mathrm{~kW} / \mathrm{m}$ line flame beneath the slab, (A-3) ignition with a $23 \mathrm{~kW} / \mathrm{m}$ line flame beneath the slab at the exposed tail edge, (A-4) ignition with a $230 \mathrm{~kW} / \mathrm{m}$ line flame covering one side of the whole slab and (A-5) ignition with a $46 \mathrm{~kW} / \mathrm{m}$ line flame at one side of the slab beside tail edge after the surface temperature of that surface had reached $150 \mathrm{C}$ by the external heating with a radiant panel. Both face burning occurred at all tests except for test A-1, and the maximum heights of flame 
tips can be summarized as shown in Figure 7. The flame height-heat release rate correlation is nearly consistent with the previous experimental correlation obtained for purer and steady heat source, and the power dependence of the flame height on heat release rate is rather weak. The maximum flame height with the both-face burning was $3.5 \mathrm{~m}$. This is larger than the floor-tofloor height of the apartment. However, even if the flame attacks the PMMA fence upstairs, it is supposed that an intermittent flame covers only a limited part of the fence. Since vertical flame heat transfer decays strongly with distance in the intermittent flame [7], such a weak exposure of the fence to the flame should result in relatively long time to the ignition [8]. The time to ignition of the PMMA specimen and to the peak heat release rate observed in these tests were rather long; the shortest time to the peak of heat release rate was 5.2 minutes for test A-4. These suggest that although the both-face burning may explain partly the slow vertical fire spread at the beginning, it cannot be a single cause for the rapid fire spread that characdaiterizes this fire disaster.

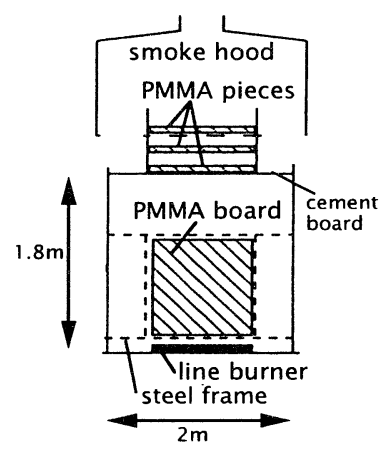

Figure 6 Experimental Setup (Indoor)

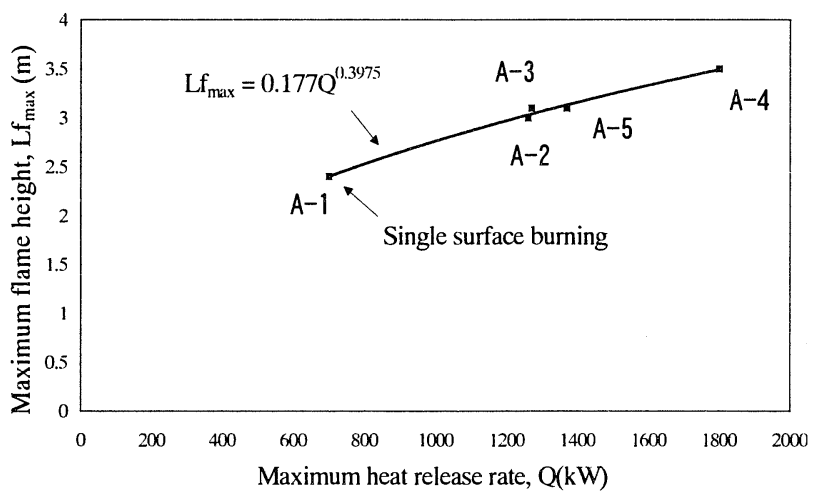

Figure 7 Maximum Heat Release Rate vs. Maximum Flame Height

\section{Merging of Vertical Flames and Involvement of the Combustible Packages on the Balcony into Fire}

Using a full-scale mock-up shown in Figure 8, a series of full-scale tests were conducted outdoors to observe the detail of the fire spread between floors. PMMA vertical slabs were installed on the two levels of balconies and on the roof to see the fire spread to the third level. In most of the seven tests conducted, such untreated combustibles as foamed plastics, fabric and mattresses were arranged on the upper balcony. An untreated acrylic curtain was hung at the location of the glass window. The $35 \mathrm{~mm}$ gap between the fence and the balcony slab was reproduced. Heat fluxes near the fence and at the location of the glass window were measured with Schmidt-Boelter gages on the upper floor. A cabled video camera was installed on the upper balcony to monitor the fire spread on the balcony. Heat release measurement was not conducted due to the limitation of the facility. The weather during the tests was relatively 
mild, and there was $1-3 \mathrm{~m} / \mathrm{s}$ north wind, from the back of the mock-up. Since only the limited numbers of floors were reproduced, the flame merging effect was studied using a $2 \mathrm{~m}$ square porous propane burner installed on the balcony of the first floor.

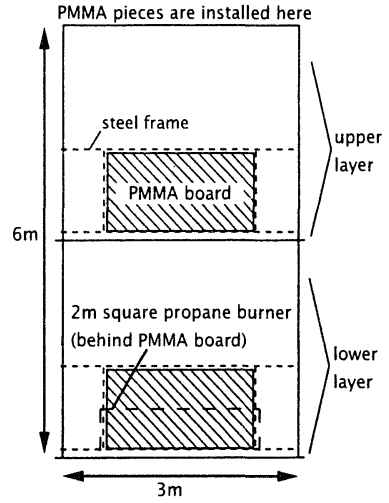

$\begin{array}{ll}\text { Figure } 8 & \text { Experimental } \\ & \text { Setup(Outdoor) }\end{array}$

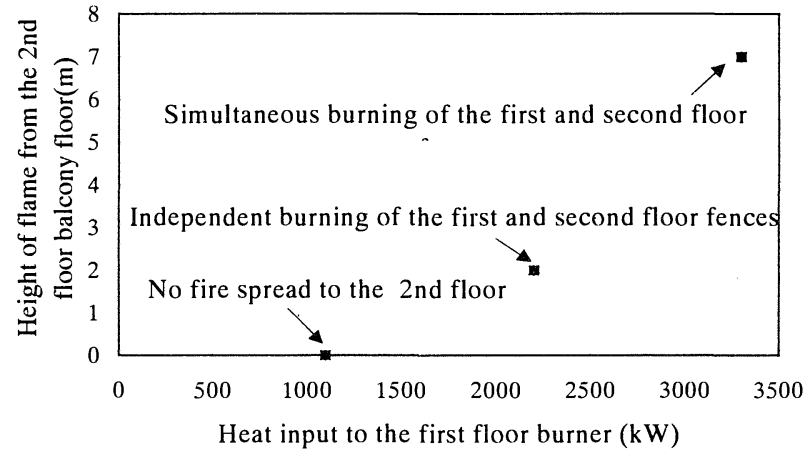
Figure 9 Total Flame Height from the $2^{\text {nd }}$ Floor Balcony vs. Heat Input to the Burner on the $1^{\text {st }}$ Floor

The flame merging effect was studied by measuring the height of the flame from the second floor balcony and the threat of the ignition on the PMMA fence on the roof through changing the heat release rate from the burner on the first floor. Figure 9 is a summary of the flame height measured from the floor of the 2 nd floor balcony and the heat input supplied from the burner. The flame from the first floor with nominal $1100 \mathrm{~kW}$ (assuming complete combustion) source finally did not ignite the PMMA fence on the second floor level. Although nominal $2200 \mathrm{~kW}$ and $3300 \mathrm{~kW}$ propane fires on the first floor were able to ignite the PMMA fence on the second floor level, resultant fire spread was significantly different between the two fire source intensities as seen in Figure 9. Although the flametips from the nominal $2200 \mathrm{~kW}$ fire reached the fence on the second floor, the flames from the first and the second floors were rather separate and the flame scarcely attacked the PMMA strips on the roof. On the other hand, with the $3300 \mathrm{~kW}$ fire source, the two flames were merged into a flame tall enough to cover and ignite within 20 seconds the PMMA strips on the roof.

Fire on the second floor level started always by the ignition of the external surface of the PMMA fence, and no fire penetration through the gap was observed prior to this ignition. The cabled video camera captured a thorough process of the fire spread from the ignition to the external surface of the fence to the full involvement of the fence and the combustible packages on the balcony. This can be summarized as shown in Figure 10. The observations in the outdoor tests can be summarized as follows. 
(1) Penetration of the gap

No flame penetration through the gap between the fence and the balcony slab was observed. It is rational as a flame developing outside the fence should make a negative pressure on the outer side of the fence to its inner side. If it is the mechanism preventing the penetration, any strong wind against the fence might resolve the negative pressure and cause a penetration.

(2) Merging effect

Combined burning of the both-face of the fence and the combustibles produced only a flame weakly touching the fence on the upper level, but was still not able to ignite it.

Combination of a burner flame enough to cover the fence and the burning of the fence and the combustibles produced a tall flame enough to ignite quickly the fence above the roof. This demonstrates the significance of the merging effect in façade fires.

(3) Fire spread from the outer surface to the inner surface of the fence

Once the burner on the lower level was fed enough fuel to cover the whole fence surface and the outer surface of the fence started to burn, clothing and other combustible objects on the balcony was ignited very quickly. The flame above the combustibles then flew to the inner surface of the fence, and ignited it. The combustibles on the balcony are thus believed to play an important role as a "mediator" for the development of fire from the outer surface of PMMA to its inner surface even if the heat release from them is not pronounced.

(4) Penetration of the glass window by fire

According to the heat flux measurement, notable heat flux exceeding $20 \mathrm{~kW} / \mathrm{m}^{2}$ was observed at the location of the window only when either the combustibles on the balcony were burning or a part of the flame outside the fence hit the balcony ceiling and flew horizontally beneath the ceiling toward the window. Sustained ignition of the curtain occurred only after such events. This suggests that fire penetration of a window fast enough to prevent effective fire fighting should take place only when the external flame becomes higher than the balcony ceiling or notable amount of combustibles on the balcony starts to burn, although weaker radiation may also result in slower penetration of glass window by fire. This may partly explain the weak damage to the interior in the $11^{\text {th }}$ floor where the fire load on the balcony was small.

\section{CONCLUSION}

The estimated controlling mechanism for the vertical fire spread though balconies can finally be summarized as shown in Figure 10. The discrete arrangement of vertical PMMA along the balcony and combustibles behind the fence are believed to have augmented the total heat release through simultaneous burning of the both sides of the fence and the combustibles, though many laboratory tests dealing with pure surface burning suggest that such discrete arrangement generally delay or prevent flame spread. The significance of the merging effect implies importance of fire protection strategy to limit a fire to first one or two stories in high-rise buildings. 
(1) Exposure of the Fence to the External Flame from Lower Floors
(2) Heating and Ignition of the Combustibles by the External Flame

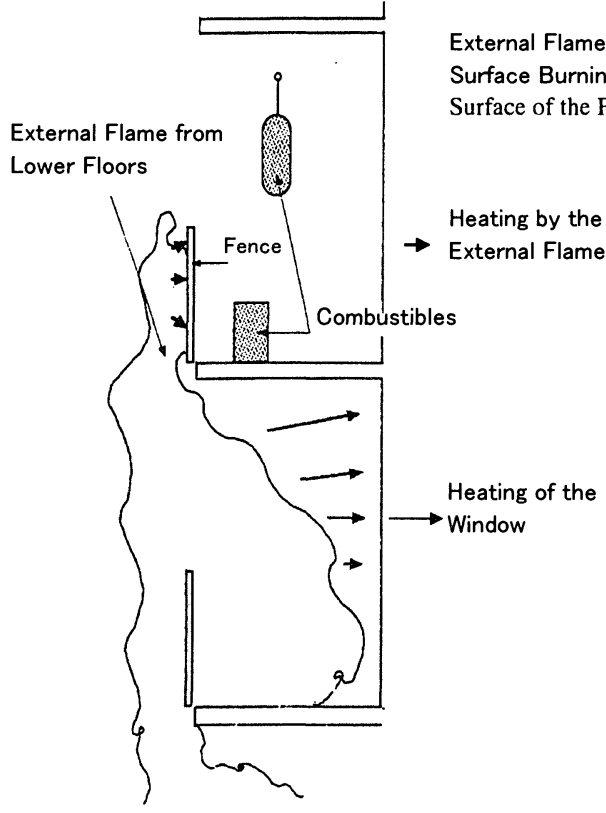

(3) Heating and Ignition of the Inner Surface of the Fence by the Burning Objects on the Balcony

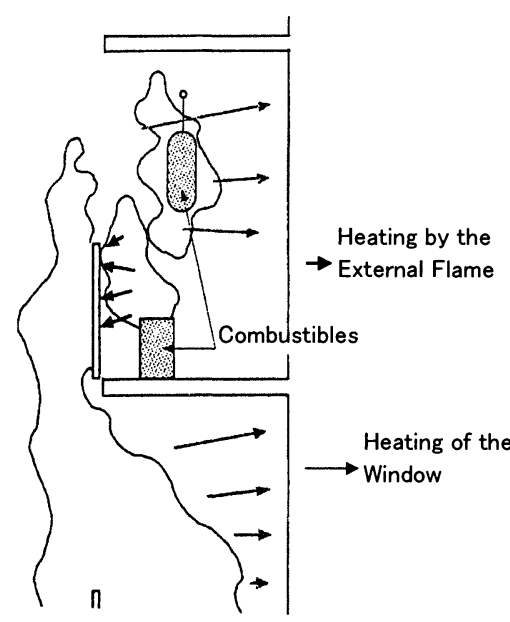

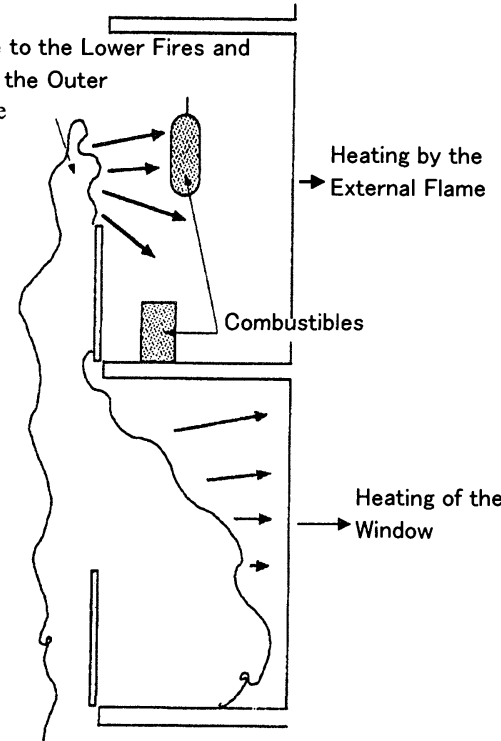

(4) Further Fire Development to the Upper Floor

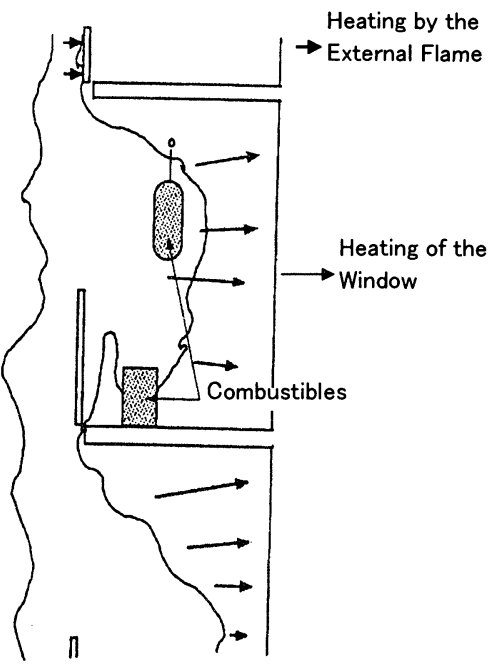

Figure 10 Estimated Controlling Mechanism for the Vertical Fire Spread through Balconies 
Hiroshima City decided to replace the PMMA fence with noncombustible ones after this study. This is believed to reduce significantly the risk of floor-to-floor fire spread in this complex.

\section{ACKNOWLEDGMENT}

The authors wish to acknowledge the partial support for the tests and the cooperation in the site investigation by Hiroshima City. The authors acknowledge especially the efforts of Messrs. T. Nakaoka, Y. Tamura and other fire fighting team of Hiroshima City throughout the investigation and the experiments.

\section{REFERENCES}

[1] Hokugo, A., Hayashi, Y., Goto, T., Harada, K., Tanaka, T., and Hasemi, Y. : $\quad$ Upward Fire Spread over the Balconies of a High-rise Apartment Building, Part 1, Proceedings of the 1997 Annual Meeting of Japan Association for Fire Science and Engineering, May 1997, Nagoya. (in Japanese ).

[2] Hasemi, Y., Hayashi, Y., and Hokugo, A. : Upward Fire Spread over the Balconies of a High-rise Apartment Building, Part 2, ibid, 1997.( in Japanese ).

[3] Hayashi, Y., Hasemi, Y., Hokugo, A., Yoshida, M., Goto, T., Yoshikawa, T., Oomiya, Y., and Takaike, R. : Upward Fire Spread over the Balconies of a High-rise Apartment Building, Part 3, ibid, 1997.( in Japanese ).

[4] Back, G., Beyler, C., DiNenno, P., and Tatem, P., Wall Incident Heat Flux Distributions Resulting from an Adjacent Fire, Proceedings of the Fourth International Symposium on Fire Safety Science, p.241-252, 1994, Ottawa.

[5] Hasemi, Y., and Tokunaga, T. : Some Experimental Aspects of Turbulent Diffusion Flames and Buoyant Plumes from Fire Sources against a Wall and in a Corner of Walls, Combustion Science and Technology, Vol.40, No.1, 1984.

[6] Hasemi, Y., and Nishihara, M. : Fuel Shape Effect on the Deterministic Properties of Turbulent Diffusion Flames, Proceedings of the Second International Symposium on Fire Safety Science, p.275-284, 1988, Tokyo.

[7] Hasemi, Y. : Thermal Modeling of Upward Flame Spread,Proceedings of the First International Symposium on Fire Safety Science, Gaithersburg, 1985.

[8] Walton,W., and Twilley, W. H. : Heat Release and Mass Loss Rate Measurements for Selected Materials, NBSIR84-2960, 1984. 